\title{
ANÁLISE ESPACIAL EM GEOGRAFIA
}

\section{Spatial Analysis in Geography}

Prof. Dr. Roberto Rosa

Universidade Federal de Uberlândia

Av. João Naves de Ávila, 2160, Santa Mônica, CEP: 38400-902 - Uberlandia, MG - Brasil Tel/Fax: (+55 34) 32394221 / 32394210 - rrosa@ufu.br

\section{${ }_{a} a \boldsymbol{a} a a$}

\begin{abstract}
Resumo
Pensar em termos espaciais pode ser uma abordagem para todo cidadão não apenas como um meio de compreender melhor o mundo e seus conflitos, mas também a situação local em que nos encontramos. A análise espacial está obrigatoriamente associada à Geografia, corresponde ao estudo da distribuição espacial de qualquer fenômeno, à procura de padrões espaciais. A análise espacial faz a ligacão entre o domínio essencialmente cartográfico e as áreas de análise aplicada, estatística e a modelagem, permitindo combinar variáveis georreferenciadas e, a partir delas, criar e analisar novas variáveis. Os avanços tecnológicos ocorridos nos últimos anos, tem contribuído para a disseminação e popularização das tecnologias que possibilitam análise espacial. Face ao exposto, este trabalho tem como objetivo apresentar uma breve discussão dos processos envolvidos na aquisição de dados, representação gráfica e na análise espacial, abordando aspectos conceituais e teóricos, bem como, os principais softwares usados para este fim.
\end{abstract}

Palavras-chave: Análise espacial, representação gráfica, geotecnologias

\begin{abstract}
Thinking in spatial terms may be a viable approach for all citizens, not only as a means of better understanding the world and its conflicts, but also the local situation in which we find ourselves. Spatial analysis is inextricably associated with Geography, and corresponds to the study of the spatial distribution of any phenomenon, with the objective of identifying spatial patterns. Spatial analysis links the specific domain of cartography with the areas of applied analysis, statistics, and modeling, which permits the combination of georeferenced variables and the creation and analysis of new variables based on these results. The technological advances that have occurred in recent years have contributed to the divulgation and popularization of the technologies that make spatial analysis possible. Given these considerations, the present study discusses the processes of data acquisition, graphical representation, and spatial analysis, and provides a brief overview of the conceptual and theoretical aspects, as well as the principal types of software used for these analyses.
\end{abstract}

Key words: Spatial analysis, graphical representation, geotechnologies

\section{Resumen}

Pensar en términos espaciales puede ser un abordaje para todo ciudadano no apenas como un medio de comprender mejor el mundo y sus conflictos, sino también la situación local en que nos encontramos. El análisis espacial está obligatoriamente asociado a la Geografía, corresponde al estudio de la distribución espacial de cualquier fenómeno, a la búsqueda de patrones espaciales. El análisis espacial hace el encuentro entre el dominio esencialmente cartográfico y las áreas de análisis aplicada, estadística y a modelaje, permitiendo combinar variables georreferenciadas y, a partir de ellas, crear y analizar nuevas variables. Los avances tecnológicos ocurridos en los últimos años, han contribuido para la diseminación y popularización de las tecnologías que posibilitan un análisis espacial. Por lo expuesto, este trabajo tiene como objetivo presentar una breve discusión de los procesos envueltos en la adquisición de datos, representación gráfica y en el análisis espacial, abordando aspectos conceptuales y teóricos, así como también, los principales softwares usados para este fin.

Palabras-Clave: Análisis espacial, representación gráfica, geotecnologías 


\section{INTRODUÇÃO}

Desde os tempos remotos até a atualidade, as informações e dados espaciais têm sido apresentados de forma gráfica pelos antigos geógrafos e cartógrafos e, utilizados por navegadores e demais profissionais. A coleta de informações sobre a distribuição geográfica de recursos minerais, propriedades rurais e urbanas, animais e plantas sempre foi uma parte importante das atividades das sociedades organizadas. A obtenção de informações sobre a distribuição geográfica dos recursos naturais alavancou o desenvolvimento de inúmeros países, permitindo a ocupação territorial.

A profissão de Geógrafo tem grande importância desde a antiguidade, pois influencia nas estratégias políticas e nos planos e ações governamentais, sendo os mapas seu principal instrumento de trabalho. Em qualquer que seja a área de atuação, devemos estar conscientes de que nosso trabalho na sociedade é o de saber pensar o espaço para que ali se possa agir, tornado este espaço melhor. A representação complexa da realidade que construímos é uma das bases da análise espacial. O pensamento espacial é fundamental para a compreensão de fenômenos naturais e sociais. A aprendizagem de conceitos de análise espacial pode contribuir para uma melhor compreensão de outras disciplinas, sendo necessário entender de: escalas, sistemas de coordenadas, projeções cartográficas e simiologia gráfica.

Só conhecendo o espaço e percebendo as relações existentes entre os vários fenômenos no nível espacial se torna possível agir sobre esse espaço. Pensar em termos espaciais pode ser uma ferramenta para cada cidadão não apenas como um meio de compreender melhor o mundo e seus conflitos, mas também a situação local em que nos encontramos. A análise espacial está, obrigatoriamente associada à Geografia, corresponde ao estudo da distribuição espacial de qualquer fenômeno, à procura de padrões espaciais.

A análise espacial faz a ligação entre o domínio essencialmente cartográfico e as áreas de análise aplicada, estatística e a modelagem, permitindo combinar variáveis georreferenciadas e, a partir delas, criar e analisar novas variáveis. Analisar significa fragmentar, decompor em partes ou componentes visando uma identificação da estrutura e compreensão de um sistema. A complexa realidade do espaço geográfico pode ser, em um contexto de análise espacial, fragmentada nas suas componentes ou derivadas obtidas a partir de uma base informativa geral. Assim análise espacial significa também extrapolação e criação de nova informação susceptível de permitir uma melhor compreensão, numa perspectiva isolada ou integrada.

No Brasil, assim como nas demais partes do mundo, os avanços tecnológicos ocorridos nos últimos anos, com o aumento do poder e velocidade de processamento dos computadores, com as novas tecnologias de armazenamento, com a queda significativa nos preços dos equipamentos e softwares, com a maior oferta de dados de sensores remotos, aliado à diminuição nos custos de aquisição e conversão de dados, tem contribuído para a disseminação e popularização das tecnologias que possibilitam análise espacial.

Face ao exposto, este trabalho tem como objetivo apresentar uma breve discussão dos aspectos envolvidos na aquisição de dados, representação gráfica e na análise espacial, abordando aspectos conceituais e teóricos e, principais softwares usados na análise espacial.

\section{ASPECTOS CONCEITUAIS}

No Brasil as tecnologias que permitem automatizar a análise espacial são conhecidas como: Geomática, Geoprocessamento, Sistema de Informação Geográfica e mais recentemente Geotecnologias. Embora cada termo apresente um conceito diferente, abordam mais ou menos a mesma temática. Estes conceitos são bastante discutidos nas obras de Tomlin (1990), Maguire et al. (1993 e 1997), Câmara et al. (1996), Burrough \& McDonnell (1998), Xavier da Silva e Zaidan (2004), Tomlinson (2005) e Demers (2009). 
O termo Geoprocessamento é usado quase que exclusivamente no Brasil, provavelmente fruto de rivalidades de intelectuais entre as correntes européias e americanas. A seguir apresentamos os conceitos que a nosso ver melhor caracterizam cada uma destas tecnologias.

Geotecnologias - conjunto de tecnologias para coleta, processamento, análise e disponibilização de informações com referência geográfica. São compostas por soluções de hardware, software e peopleware que juntas constituem-se em poderosos instrumentos como suporte a tomada de decisão. Dentre as geotecnologias podemos destacar: a cartografia digital, o sensoriamento remoto, o sistema de posicionamento global, o sistema de informação geográfica, e os aplicativos gráficos disponíveis na WEB (Google Maps, o Google Earth, o Microsoft Virtual Earth, Google Street View, etc.).

Geomática - Ciência que se utiliza de técnicas matemáticas e computacionais para a análise de informações geográficas, ou seja, informações temáticas “amarradas" à superfície terrestre, através de um sistema de coordenadas. No Brasil, o termo Geoprocessamento e Geomática se referem à mesma coisa, ou seja, Geoprocessamento é utilizado como sinônimo de Geomática.

Sistema de Informação Geográfica - Conjunto de ferramentas computacionais, composta por equipamentos e programas que, por meio de técnicas, integra dados, pessoas e instituições, de forma a tornar possível a coleta, o armazenamento, o processamento, a análise, a modelagem a simulação e a disponibilização de informações georreferenciadas, que possibilitam maior facilidade, segurança e agilidade nas atividades humanas, referentes ao monitoramento, planejamento e tomada de decisão, relativas ao espaço geográfico.

\section{AQUISIÇÃO DA INFORMAÇÃO}

Para realizar uma análise espacial, torna-se necessário ter informação sobre a qual se vai trabalhar. Dados, são observações diretas da realidade, ou seja, são uma coleção de fatos que podem ser armazenados, processados e transformados em informação. Podemos pensar em dados como uma lista de números e, a informação é o significado que atribuímos aos dados. A informação pode aparecer de várias maneiras e sob vários formatos. Pode ser sob a forma de texto, números, gráficos ou imagens. Pode ainda estar associada a uma localização geográfica ou não. Os dados sob a forma de texto ou números denominam-se alfanuméricos e podem estar organizados em tabelas, podem referir-se a uma localização específica ou a um momento (no tempo) específico.

A produção de informação requer primeiro a coleta de dados. Os dados espaciais podem provir de fontes primárias ou fontes secundárias. Os dados devem ter três dimensões: temporal (quando), temática (o quê) e espacial (onde). Os dados temáticos são considerados atributos, ou seja, são as características referentes a uma entidade geográfica. A dimensão espacial dos dados é representada pelas $\mathrm{x}$, y e por vezes $\mathrm{z}$.

A qualidade dos dados coletados direta ou indiretamente vai determinar a qualidade do resultado final do trabalho. A qualidade dos dados pode ser avaliada quer pela sua precisão quer pela sua exatidão. A precisão dos dados corresponde ao nível de detalhe dos dados. A exatidão corresponde ao grau de aproximação dos valores relativamente à realidade. Os dados nunca são cem por cento precisos nem exatos, mas os seus níveis de precisão e exatidão devem ser os maiores possíveis, para que o erro seja o menor possível.

Podemos também trabalhar com variáveis discretas ou contínuas. Uma variável discreta é uma variável que pode ser localizada com precisão, através das suas coordenadas geográficas. As variáveis contínuas são aquelas que podem ser medidas em qualquer lugar da superfície terrestre (como a altitude, a temperatura, tipo de solo) e onde se torna difícil a definição das suas fronteiras, uma vez que geralmente há uma passagem gradual entre duas características diferentes.

A diferença entre informação geográfica e não geográfica relaciona-se com a localização dos elementos, ou seja, ao georreferenciamento. A informação não geográfica é a que geralmente 
aparece nas legendas dos mapas, ou seja, os atributos de cada local (população, mortalidade, PIB, etc.). Portanto, pode ser representada nos mapas, mas também sob a forma de tabelas e gráficos.

O conceito de informação geográfica não se limita à informação cartográfica, ele deverá ser entendido, como sendo todo tipo de dados diretamente materializados sobre a representação cartográfica e susceptível de análise espacial, ou seja, toda informação quantitativa (ex. dados censitários) e qualitativa (ex. tipo de solo), desde que possa ser referenciada a uma área.

Também é possível pensar em tipos de dados de acordo com o tema a que se refere, desta forma, em análise espacial pode-se trabalhar com dados ambientais ou físicos (ex. altitude, temperatura, solos, etc.), como também com dados socioeconômicos (ex. população, economia, indústria, comércio, transporte, etc.).

Os dados socioeconômicos geralmente são coletados dentro de limites administrativos (países, estados, municípios, setores censitários), ao passo que os dados ambientais e físicos nem sempre correspondem a esses limites. Um fenômeno natural não se restringe a uma área porque existe um limite de um estado ou município. Portanto, muitas vezes torna-se necessário aplicar determinadas operações aos dados para que se possam correlacionar.

\section{ESCALAS DE MEDIDA DOS DADOS}

Os dados podem representar escala de medidas booleanas, nominais, ordinais de intervalo e de razão. Este aspecto é muito importante porque só conhecendo o tipo de escala de medida se pode perceber que tipo de operações pode-se aplicar aos dados.

Escala booleana ou binária - nessa categoria incluem-se os dados em que apenas se identifica a sua existência ou ausência. Por exemplo, os países da América do Sul que fazem parte do MERCOSUL. Na base de dados, poderá aparecer apenas Sim ou Não ou até Verdadeiro ou Falso.

Escala nominal - nesta categoria encontram-se os dados cujo significado é apenas descritivo como um nome. Um número de telefone ou um código postal, são números que não têm valor aritmético porque são dados nominais. Um número de telefone não é o dobro do outro, nem é superior a outro, é apenas diferente. Não se podem fazer operações entre números de telefone. Não tem qualquer significado ordenar, somar ou multiplicar estes dados.

Escala ordinal - nesta categoria encontram-se os dados que se podem ordenar ou hierarquizar. Como exemplo, podemos citar a escala de dureza dos minerais, a classificação hoteleira, os níveis de escolaridade, a posição de um atleta em uma corrida, etc. As operações matemáticas não tem significado.

Escala de intervalo - esta categoria inclui dados, que se representam, em escalas de valores definidas. Por exemplo, escalas de temperatura, eqüidistância entre curvas de nível. Nesta escala, faz sentido adicionar ou subtrair valores, mas a multiplicação ou a divisão não tem significado. A escala de intervalo não começa necessariamente no zero. A existência de valor zero não corresponde à ausência desse fenômeno.

Escala de razão - nesta escala, os números têm um significado aritmético. O zero corresponde à ausência do fenômeno e qualquer operação matemática pode fazer sentido. Podemos aqui fazer operações entre atributos e calcular, por exemplo, densidades.

É comum encontrar bases de dados onde aparecem dados de diferentes tipos, tornando-se importante conhecer os dados para que se possa saber quais as operações que se podem efetuar entre tais dados.

\section{CLASSIFICAÇÃO DOS DADOS}

Os valores ordinais, de intervalo e as razões podem agrupar-se em classes, sobretudo se a amplitude de valores é grande. Se cada elemento fosse cartografado com um símbolo único, seria 
muito difícil encontrar elementos de valores idênticos. A maneira como se definem os limites de intervalo de cada classe vai determinar que elementos devem ser incluídos em cada classe e logo o aspecto do mapa. Ao alterar as classes podemos obter mapas muito diferentes, o que permite uma manipulação da leitura dos dados. De forma geral, devem-se manter na mesma classe elementos mais semelhantes possíveis e devem colocar-se em classes diferentes valores o mais distintos possível.

Existem diferentes métodos para se classificar os dados tornando-se necessário atender a determinadas regras para cartografar estes valores. A divisão em classes pode ser feita manual ou automaticamente. Mitchell (1999) identifica quatro principais métodos e indica os casos mais adequados a cada um.

Limites naturais - procura agrupamentos e padrões inerentes aos dados, de modo a que os valores dentro da mesma classe tendam a ser semelhantes e valores de classes diferentes tendam a ser diferentes. Os limites definem-se onde há rupturas entre grupos de valores. Este método é bom para se cartografar valores de dados que não se distribuem equitativamente uma vez que coloca na mesma classe valores próximos, agrupando-os;

Quantis - cada classe tem o mesmo número de elementos. Os elementos são ordenados de acordo com o valor do atributo, do menor para o maior, e vai somando o número de elementos. Divide-se o total de elementos pelo número de classes que se especificou para obter o número de elementos que deve integrar cada classe. Posteriormente, atribui-se à primeira classe os primeiros elementos (de menor valor) até preencher a classe, após prossegue-se para a classe seguinte, preenchendo-a, e assim sucessivamente. Este método é útil para comparar áreas de dimensões semelhantes ou para cartografar dados cujos valores se distribuem equitativamente.

Intervalos iguais - neste método cada classe tem uma amplitude igual em termos de valor, ou seja, a diferença entre o valor máximo e mínimo de cada classe é constante. Este método é mais apropriado na cartografia de dados contínuos, como a precipitação e a temperatura.

Desvio padrão - segundo este método, cada classe é definida pela distância do valor à média de todos os elementos. Calcula-se inicialmente a média e posteriormente o desvio padrão. Pode-se pensar neste método como sendo a variação de cada valor relativamente à média. Criam-se limites de classe acima e abaixo da média com base no número de desvios padrões que se determinar.

A escolha do método a usar pressupõe que se conheçam os dados e o que significam para que a decisão do método a usar tenha alguma coerência. Uma vez decidido sobre o método a usar, há que decidir quantas classes criar. A maioria dos leitores de mapas consegue distinguir até sete cores (tons) em um mapa, portanto, usar mais do que sete classes torna-se difícil encontrar elementos com valores semelhantes. Quatro ou cinco classes geralmente revelam padrões de distribuição nos dados sem confundir o leitor. O uso de menos do que três ou quatro classes não coloca em evidência grandes variações entre os elementos.

\section{REPRESENTAÇÃO GRÁFICA}

Os elementos de representação do espaço são: pontos, linhas e áreas. A representação de uma entidade pontual é feita pela definição de um par de coordenadas (x,y). Ao representar uma entidade linear ou de área, define-se um conjunto de pontos, representados por conjuntos de pares de coordenadas. Cada conjunto de elementos corresponde a um só tipo de representação (ponto, linha ou área). Por exemplo, os municípios podem ser representados por áreas, as rodovias podem ser representadas por linhas, as sedes dos municípios por pontos.

As variáveis que acabamos de descrever são as variáveis discretas, ou seja, aquelas em que, em um determinado lugar, ela existe ou não existe. Porém, há outro tipo de variáveis, as contínuas. As variáveis contínuas são aquelas que se encontram em qualquer lugar da terra, ou seja, podem ser medidas em qualquer localização (ex. temperatura, pressão, altitude, etc.). Não existe uma definição clara dos limites entre entidades geográficas contínuas, visto que a transição entre dois 
elementos se faz gradualmente. A cartografia de variáveis contínuas é feita através de áreas delimitadas por isolinhas, ou seja, linhas que unem pontos de igual valor (curvas de nível, isotermas, isóbaras, isoietas, etc.)

Após a obtenção de informações e realizadas as análises espaciais necessárias e estando as mesmas disponíveis no monitor, há, muitas vezes, a necessidade de elaborar um mapa, que poderá ser impresso ou publicado para um determinado fim (layout). Nesta fase, deve-se levar em conta todas as regras de cartografia, incluindo os cuidados com a utilização de todos os elementos que compõem um mapa (título, legenda, escala, coordenadas e orientação). Os mapas não são reproduções totalmente fiéis da realidade porque estão sujeitos a simplificações, generalizações, omissões e projeções que distorcem inevitavelmente a informação neles contida. Cabe ao geógrafo decidir qual a informação que vai representar e qual vai omitir (quer ao nível dos objetos representados, quer ao nível de simplificação e generalização que terá de fazer). Cabe-lhe ainda a decisão de como representar a informação. Tais decisões determinarão o modo como o leitor ou o utilizador do mapa interpretarão a informação nele contida.

Ao ser elaborado, um mapa sofre uma transformação geométrica que consiste em representar em um plano o que na realidade é essencialmente esférico. Essa transformação corresponde à projeção e pode ser feita de várias maneiras. Qualquer projeção que escolhemos imprime sempre distorção quer nas dimensões quer nas formas do que se representa, por isso a escolha da projeção a usar depende da área que se vai mapear, da escala e também do objetivo do mapa. Geralmente quando se elabora um mapa de uma área pequena, como o espaço urbano, estas distorções podem ser negligenciáveis, mas quando trabalhamos com áreas maiores como um estado ou país, devemos nos preocupar com o tipo de projeção, porque os efeitos da curvatura da Terra são bastante perceptíveis.

Existem vários métodos para projetar a superfície em um plano, no entanto todos imprimem algum tipo de deformação. A complexidade das projeções é muito grande, e dentro de cada tipo de projeção existe uma enorme variedade de casos com características particulares. Uma vez escolhida a projeção, há que localizar os elementos e ou objetos e referenciá-los na superfície terrestre. $\mathrm{O}$ georreferenciamento, ou seja, a definição da localização do objeto é feita através de um sistema de coordenadas, que pode ser o geográfica ou UTM. Para trabalhar com dados que tenham sido georreferenciados a sistemas de coordenadas e projeções diferentes, pode-se realizar operações de transformação das coordenadas, ferramentas estas, disponíveis hoje em dia, na maior parte dos softwares disponíveis.

É importante saber em que sistema de representação encontram-se os dados com que trabalhamos para se poder fazer operações entre diferentes mapas. Só se pode sobrepor mapas que estejam no mesmo sistema de projeção e referência, pois é o georreferenciamento que possibilita essa sobreposição.

A elaboração de um mapa pressupõe, geralmente, um objetivo. Estabelecer esse objetivo é um dos primeiros passos a dar antes de começar a fazer o layout, uma vez que alguns dos elementos a representar e a forma de representar poderão estar dependentes dele. Posteriormente torna-se necessário selecionar os elementos que se vão representar e os que não vão ser representados (uma vez que nem toda a realidade pode estar no mapa). Os elementos representados serão depois simplificados e generalizados. Em seguida é necessário acrescentar alguns elementos que serão fundamentais na leitura do mapa, tais como o título, a legenda, a escala, as coordenadas e a orientação.

A cartografia consiste em um grupo de técnicas que se preocupam fundamentalmente com a redução das características espaciais de uma área, colocando-as em um mapa de modo a torná-las observáveis. Os mapas são representações reduzidas de uma parte da realidade. São representações simplificadas da superfície da Terra, ou de parte dela, para muitos e vários fins. Portanto, a função e o objetivo dos mapas são várias, sendo que em sua concepção deve-se levar isso em consideração. 
O leitor é quem detecta, discrimina e identifica o que está representado no mapa, já o utilizador vai mais além, chegando ao um estágio de compreensão da informação contida no mapa. Um utilizador lê, analisa e interpreta um mapa. O geógrafo ao elaborar um mapa, deve produzir mapas diferentes para leitores e utilizadores diferentes. Quem efetua formas de pesquisa visual é o leitor, quem utiliza ferramentas de análise espacial e processos mais complexos é o utilizador.

É importante percebermos de que os mapas são meios de comunicação, nesse sentido, por mais diferentes que os mapas pareçam, os métodos cartográficos envolvidos na sua elaboração são fundamentalmente similares. O mapa tem a função de informar, mas é também um meio de comunicação, pelo que as regras de cartografia devem estar de acordo com as regras de comunicação. Os fenômenos devem estar representados de modo que se consigam visualizar a estrutura espacial e a as relações espaciais entre os objetos. Para ler um mapa utilizam-se os órgãos da visão e do cérebro em estreita conexão. A percepção e a cognição são mecanismos envolvidos neste processo, portanto, é importante perceber como é que funciona a visão para definição das regras da representação cartográfica.

Bertin (1967), publicou a obra "Sémiologie Graphique” onde estão expostas as regras básicas da expressão gráfica, baseadas na análise de centenas de imagens a partir das quais definiu as variáveis visuais que se devem levar em conta quando se utiliza a expressão gráfica. Independentemente de se estar representando em um mapa um ponto, uma linha ou um polígono, os elementos cartografados podem classificar-se em variáveis visuais. Cada uma dessas variáveis caracteriza-se pelo seu nível de organização e têm ou não a propriedade de transcrever eficazmente uma diferença, uma ordem ou uma proporção. As variáveis são: o tamanho, o valor, a granulometria, a cor, a orientação e a forma.

O conhecimento das propriedades de cada variável visual e das variáveis que serão representadas é extremamente importante para o Geógrafo no momento de elaborar o mapa.

Bertin (1967) define "gráfica" como uma linguagem que utiliza as propriedades da imagem visual para mostrar as relações de semelhança e de ordem entre os dados, que constituem a parte racional do mundo das imagens. A "gráfica" tem como objetivos tratar os dados para compreendê-los e deles tirar informação e, comunicar a informação. A construção de mapas deve ser feita de maneira que sua leitura seja eficaz. Quando não se respeitam as regras da gráfica e da cartografia, a leitura do mapa fica comprometida, o que pode ser crucial na comunicação, na transmissão de informação e, em última análise, na tomada de decisões.

É importante que os usuários tomem consciência destes aspectos de forma a melhorarem os mapas que produzem. Os computadores e os softwares gráficos são instrumentos potentes e valiosos porque poupam muito tempo de trabalho, no entanto, é preciso ter alguma cautela relativamente aos automatismos. A maioria dos softwares hoje disponíveis permite a produção rápida e quase automática de layouts a partir de dados, mas a elaboração de um mapa correto e legível deve ser alvo de algum tempo gasto em frente ao computador. O espírito crítico é importante, pois as escolhas automáticas que o computador faz relativamente às cores ou aos símbolos a utilizar, nem sempre são as mais corretas do ponto de vista da simiologia gráfica.

\section{OPERAÇÕES DE ANÁLISE ESPACIAL}

Os softwares possuem ferramentas que permitem pesquisar os dados, procurando identificar elementos, padrões e tendências que a simples visualização não evidencia. Estas ferramentas podem pesquisar dados, individualmente, mas também podem fazê-lo através da combinação de vários dados. A pesquisa pode ser feita de maneira simples, apontando o cursor e procurando as características de um local até a procura de padrões através da comparação de fenômenos, ou mesmo a definição de áreas tampão que delimitam as áreas a determinadas distancias de um fenômeno. 
As operações de análise espacial são as que permitem responder a questões como "Onde fica ... ?", “O que existe aqui?", “o que fica mais perto ...?”, O que é que se encontra dentro desta área?”, “O que faz limite com ...?”. Tais operações de pesquisa são as operações iniciais de análise espacial.

A seguir apresentamos alguns tipos de análise espacial e quais são as possibilidades de análise que elas nos permitem fazer.

Sobreposição - Trata-se do método mais simples de representar vários tipos de dados que ocupam um mesmo espaço. Ela é usada quando necessitamos considerar vários atributos de uma determinada aérea. Deste modo procedemos à sobreposição de, por exemplo, mapa topográfico, um mapa da malha viária, um mapa de localização das escolas.

A sobreposição implica que as camadas (layers) sobrepostas pertençam à mesma área e se encontre no mesmo sistema de coordenadas e na mesma projeção cartográfica. A sobreposição permite observar a existência (ou não) de relação entre fenômenos diferentes que se manifestam na mesma área geográfica. A sobreposição permite identificar padrões de distribuição de fenômenos e de estabelecer relações entre eles, sendo um dos principais objetivos da análise espacial.

Pesquisa topológica - A topologia pode ser definida pelas relações existentes entre entidades espaciais. A topologia é o termo usado para descrever as características geométricas dos objetos. Estas características independem do sistema de coordenadas e da escala utilizada. Existem três tipos de relações topológicas: adjacência, estar contido e conectividade. A adjacência e o estar contido descrevem as relações geométricas que existem entre áreas. As áreas são adjacentes se tiverem um limite comum (por exemplo, o estado de Goiás está adjacente ao estado de Minas Gerais). O estar contido é uma extensão da adjacência e descreve uma área que esta toda contida dentro de outra (ex. uma ilha dentro de um rio). A conectividade é a propriedade geométrica que descreve as ligações entre linhas. As rodovias estão geralmente conectadas umas as outras, formando a malha viária. $\mathrm{O}$ mesmo acontece com a rede hidrográfica formada por um conjunto de rios e seus afluentes conectados entre si. A conectividade pode ainda descrever a propriedade existente entre duas áreas não contíguas que se relacionam de algum modo. Por exemplo, o Alaska apesar de geograficamente afastado dos Estados Unidos pertence administrativamente a este, existindo, portanto, uma relação de conectividade.

A compreensão das relações topológicas entre entidades geométricas é muito importante em análise espacial, pois permite responder a questões como "Qual a menor distância entre dois locais" ou "Quantos municípios fazem parte de uma determinada região" ou ainda "Quais os municípios que fazem limite com Goiânia?”. Assim, podem ser realizadas pesquisas procurando elementos que, relativamente a outro: o intersectam; se encontram a uma determinada distância dele; o contenham completamente; estejam completamente contidos nele; tenham o seu centro nele; partilhem um limite; sejam atravessados por ele, pesquisas estas que são baseadas na distância, ou seja, pesquisa de proximidade.

Operações de buffering -Trata-se de uma operação de distância que consiste em delimitar áreas tampão em torno de uma determinada entidade. Podem ser úteis na delimitação de áreas de preservação permanente ou de leitos de cheia dentro da qual não é permitido construir. Os buffers podem ser criados em torno de elementos pontuais, lineares ou poligonais.

Pesquisa monocamada e multicamada - É possível se trabalhar com às camada (layers) individualmente ou em conjunto. A pesquisa em monocamada corresponde à pesquisa que é feita numa só camada, sendo, portanto, a mais simples. Incluem todas as operações de pesquisa já descritas até aqui, além de operações de análise de redes, medição de distâncias, áreas e perímetros.

As operações multicamada são aquelas que se fazem em várias camadas simultaneamente, ou seja, em mapas onde existe sobreposição de vários temas vetoriais. As operações que assim se efetuam, irão atuar sobre as várias camadas, porém devemos ter cuidados, dentre os quais merecem destaque: as camadas devem estar na mesma escala, mesmo sistema de coordenadas e mesma projeção cartográfica, caso contrário a sobreposição não é possível e as pesquisas e operações a efetuar terão erros. 
Operações de geoprocessamento - As operações de geoprocessamento podem ser consideradas como operações que integram componentes de edição e princípios de análise espacial. A partir de operações espaciais com uma componente de lógica booleana (união, intersecção, etc.) ou de operações de associação da informação por junção espacial, são produzidos novos temas de informação geográfica ou enriquecidas tabelas já existentes.

As operações de geoprocessamento mais freqüentes são:

Dissolução (dissolve) - esta operação agrega elementos que tenham atributos comuns. Por exemplo, pode-se fazer uma dissolução de todos os municípios que pertencem ao triangulo mineiro, transformando-se assim, um mapa de municípios em um mapa de uma região.

Junção (merge) - esta operação junta dois ou mais mapas ou camadas adjacentes através dos seus atributos comuns. Permite manter os atributos se eles estiverem identificados com o mesmo nome. Como exemplo, podemos juntar duas folhas contíguas com a malha viária. Para que duas camadas possam se juntar, elas têm de corresponder ao mesmo tipo de entidades, isto é, não se podem juntar linhas com polígonos ou pontos com linhas.

Corte (clip) - esta operação permite cortar uma camada tendo como molde outra camada. $\mathrm{Na}$ camada resultante, mantêm-se os atributos da camada inicial, não os da camada que serviu de molde. Por exemplo, se desejarmos cortar um determinado município do mapa dos municípios do estado de Goiás, o mapa do estado será a camada inicial, o município a ser recortado será o molde e o mapa resultante (município em questão) manterá as características existentes na camada do estado de Goiás.

Intersecção (intersect) - é uma operação semelhante ao corte, porém a diferença fundamental é que a camada resultante mantém os atributos de ambas as camadas usadas para o corte (da camada inicial e da camada de molde).

União (union) - esta operação corresponde a uma intersecção onde o corte não foi efetuado, ou seja, ao fazer uma união entre duas camadas, a camada resultante terá a área da camada maior e manterá os atributos de ambas as camadas.

Análise de Redes - As redes, são um sistema de linhas que se encontram interligadas, representando o movimento de um fenômeno ao longo dessas linhas. Podem representar a trajetória de um rio, o transporte de mercadorias ou serviços, o fluxo de uma rede elétrica ou o fluxo de comunicação em uma rede telefônica o de internet.

A análise de redes, correspondem a um conjunto de operações de análise de grande utilidade para várias áreas, sendo uma excelente ferramenta de planejamento, quer para empresas que necessitam planejar rotas de distribuição, quer para serviços públicos como as companhias de energia e água ou até mesmo para o cidadão comum que precisa planejar uma viagem ou alterar o seu trajeto diário até o trabalho.

Portanto, as redes são compostas por linhas que correspondem a caminhos por onde se movimentam pessoas, bens, serviços ou informação (ferrovia, rio, estrada). No entanto, não é necessária a existência real de elementos lineares, como exemplo podemos citar a rede de telefonia celular, cujo as linhas não existem fisicamente.

As linhas de uma rede encontram-se interligadas por nós. Um nó corresponde a uma ligação entre duas linhas. O nó pode representar o ponto onde um afluente se encontra com o rio principal, um ponto de metrô, um posto de combustível, um serviço telefônico, etc. Um nó pode representar um ponto de partida ou um ponto de chegada. Uma rede pode representar o caminho em um ou ambos os sentidos, mas é importante conhecer o sentido do fluxo. É importante considerar também, 
que duas linhas podem se cruzar sem se intersectarem. Neste caso, à intersecção das duas linhas não é um nó, pois os nós indicam que as linhas estão ligadas entre si.

Quando tratamos de redes, uma análise muito utilizada é a de acessibilidade. A acessibilidade é a maior ou menor facilidade de chegar a um determinado local. A acessibilidade depende de outros fatores além da distancia real. As mais evidentes são à distância-tempo e a distância-custo. À distância-tempo corresponde ao tempo que se demora a chegar a um determinado local. À distância-custo corresponde ao custo que se tem para se chegar a um determinado local. Convém destacar que o termo "custo" pode assumir aqui diversos significados, não se restringindo ao custo financeiro. Estes conceitos são importantes em análise espacial e em modelagem, porque no estudo de uma rede de transporte, por vezes há que considerar estes dois fatores (tempo e custo), que nem sempre tem o mesmo peso na análise. Em determinados casos pode ser mais importante chegar depressa a um lugar, mesmo que isso custe mais caro.

A análise de redes é muito útil no estudo de acessibilidades. Esta pode ser mais ou menos completa, considerando as variáveis estudadas. Podem ainda ser feitas análises comparativas e procurar os trajetos mais eficientes nos vários tipos de distâncias: procurar o trajeto mais rápido, o trajeto mais barato, ou o trajeto com menor distância. A maior dificuldade está em conhecer exatamente os fatores que influenciam a acessibilidade, bem como o peso a atribuir a cada um deles. Ou seja, a complexidade dos modelos de análise de redes reside nos conhecimentos de quem faz a análise e na sua capacidade em identificar e quantificar os fatores que são mais importantes.

Em análise de redes é importante perceber que a um determinado local está associada uma área até onde o seu impacto se faz sentir. Este impacto pode ser determinado por vários fatores. Por exemplo, a área de influência de uma padaria corresponde à área onde moram seus clientes, fora desta área, os consumidores farão as suas compras em outra padaria.

Modelagem Tridimensional - Os modelos tridimensionais têm a vantagem de mostrar perspectivas diferentes de um fenômeno. São usados geralmente para fenômenos contínuos para ajudar à visualização da superfície. Para criar uma perspectiva tridimensional especificam-se três parâmetros que determinam o aspecto da vista: a localização do observador, o exagero vertical e a localização da fonte luminosa.

Interpolação - As variáveis contínuas são representadas por áreas que se denominam superfícies. É impossível colher dados sobre todos os pontos da superfície da Terra. Para serem cartografados, os dados das variáveis contínuas começam por ser um conjunto de dados de uma amostra. Depois, os valores de qualquer ponto no espaço entre as amostras, são determinados estatisticamente e serão tanto mais exatos e precisos quanto mais pontos de amostra houver.

O processo matemático pelo que se estima o valor de uma característica em locais onde essa característica não foi medida chama-se interpolação. Há vários algoritmos matemáticos para realizar cálculos de interpolação, ou seja, existem vários tipos de interpoladores. Basicamente, o que um interpolador faz é estimar um valor de uma variável em qualquer ponto da superfície. Um interpolador procura preencher o espaço com valores de uma determinada variável, com base em pontos de amostragem. Quantos mais pontos de amostragem houver, mais precisa será a estimativa calculada pelo interpolador. O calculo pode ser feito de diversas maneiras, pois há vários métodos de interpolação e muitas vezes a dificuldade está em escolher o método que melhor se aplica ao estudo que se pretende fazer, uma vez que diferentes métodos podem produzir diferentes resultados.

Modelagem Cartográfica - Um modelo cartográfico é uma representação gráfica dos dados e dos procedimentos analíticos usados em um estudo, seu propósito é ajudar o analista a organizar e estruturar os procedimentos que serão usados e a identificar os dados necessários. Portanto, um modelo é um conjunto de regras e procedimentos para representar um fenômeno e prever um resultado, consiste numa sequência de processos ligados uns aos outros.

Os modelos reproduzem determinados aspectos da realidade. Quantos mais fatores são levados em conta no modelo, mais complexo ele se torna, mais dispendioso e mais pesado em termos 
computacionais. Nem sempre um modelo mais complexo é o melhor, tudo depende da questão que se quer resolver.

A modelagem é uma aproximação metodológica que integra um conjunto de processos visando a resolução de problemas espaciais. Um modelo serve para testar cenários alternativos, alterando variáveis e por vezes até serve para fazer previsões.

Uma das vantagens da modelagem cartográfica está na clareza de esquematização dos dados e do seu processamento. A desvantagem é que este método mostra apenas uma visão associada aos dados que se escolheu colocar como variáveis no processo, podendo ter ficado de foram outros dados, outras relações e outros processos. Um modelo será tanto mais útil e correto quanto mais variáveis se conseguirem usar, seus erros estão no fato de não ser possível identificar todas as variáveis intervenientes no processo.

O processo de representar esquematicamente um modelo é através da álgebra de mapas, que consiste numa forma de organizar os métodos através dos quais as variáveis e as operações vão desenvolver o modelo. Os conceitos da álgebra de mapas são semelhantes aos da matemática, ou seja, seguem uma lógica e uma terminologia através da qual se compõem esquemas ou equações, sendo que estas equações podem ser simples ou complexas. Da mesma forma que em matemática se usam símbolos para representar valores reais ou variáveis, em álgebra de mapas usam-se símbolos para representar as variáveis geográficas. Paralelamente aos operadores matemáticos (soma, subtração, multiplicação e divisão), também se usam operadores lógicos para representar as relações entre variáveis ou as combinações entre mapas.

Após identificar as camadas e os conjuntos de dados que entrarão no modelo, desenvolve-se um processo de passagem dos dados iniciais para a solução final, através de uma linguagem simples, clara e lógica, esquematizado em um fluxograma, onde se observam as várias camadas, as várias operações de transformação que essas camadas vão ser submetidas e ainda os comandos do programa de SIG que permitem realizar tais operações. Estes esquemas podem ser altamente complexos e elaborados, dependendo da complexidade do modelo. Os SIG permitem, por meio de suas funções de análise espacial, conceber, implementar e executar os modelos.

\section{ALGUNS SOFTWARES USADOS NA ANÁLISE ESPACIAI}

$\mathrm{Na}$ Internet, pode-se encontrar uma grande variedade de softwares de forma a atender às mais variadas necessidades de análise espacial. Há programas de computador que servem mais ao uso acadêmico, com a finalidade de difundir os conceitos e procedimentos metodológicos desta tecnologia e, outros, mais voltadas a aplicações profissionais, como exemplo: agronegócio, defesa, energia elétrica, telecomunicações, logística, meio ambiente, gestão governamental, etc. A seguir são apresentados alguns dos mais usados no Brasil.

ArcGIS - O ArcGIS Desktop é um conjunto de softwares que roda em microcomputdores. São usados para criar, importar, editar, buscar, mapear, analisar e publicar informações geográficas. Quatro softwares compõem o conjunto ArcGIS Desktop; cada um acrescenta um nível superior de funcionalidades, são eles: ArcReader, ArcView, ArcEditor, ArcInfo. Todos os produtos ArcGIS Desktop compartilham a mesma arquitetura, desta forma, usuários de quaisquer um dos softwares ArcGIS Desktop podem compartilhar seu trabalho entre si. Documentos de mapas, dados, símbolos, definições de apresentação dos temas, relatórios, metadados, modelos, interfaces e ferramentas customizadas entre outros, podem ser intercambiados livremente entre os usuários destes softwares. Além disso, os produtos criados no ArcGIS Desktop podem ser compartilhados com muitos usuários por meio de aplicações customizadas com ArcGIS Engine e sofisticados serviços de SIG para Web, por meio do ArcIMS e do ArcGIS Server.

ArcInfo - O ArcInfo é o mais completo e extensível software de SIG disponível. Além de incluir todos os recursos disponíveis no ArcView e ArcEditor, o ArcInfo oferece um conjunto de aplicações que permitem ao usuário realizar operações sofisticadas de SIG e conversão de dados. 
O ArcInfo oferece recursos que permitem aos usuários executar todas as atividades de SIG dentro de um fluxo de trabalho, desde a concepção, modelagem, conversão e tratamento dos dados, às análises espaciais e elaboração de mapas para apresentação. O ArcInfo dispõe de todos os recursos necessários para a criação e o gerenciamento de uma estrutura inteligente de SIG, a partir de uma interface fácil e intuitiva, que ainda pode ser customizada por meio de modelos, scripts e aplicações. Os recursos do ArcInfo permitem ao usuário criar geodatabases por meio da conversão de outros formatos, incluindo CAD ou pela importação de esquemas pré-definidos em ferramentas CASE. O ArcInfo ainda suporta todas as operações administrativas para a manutenção da integridade das bases de dados, inclui a extensão ArcScan, ferramenta para vetorização semi-automática de dados, que pode ser usada na conversão de acervos de plantas digitalizadas. Possui ferramentas exclusivas para automação de tarefas relacionadas à elaboração de mapas cartográficos de alta qualidade.

ArcView - ArcView é uma software SIG rico em funcionalidades para visualização, gerenciamento, elaboração e análises de dados geográficos. Com o ArcView é possível entender o contexto geográfico dos dados, permitindo entender relacionamentos e identificar padrões de distribuição espacial. O ArcView é usado com sucesso por milhares de organizações para auxiliar nos processos de análises espaciais e suporte a tomada de decisão. O ArcView é o SIG desktop mais popular, por ser de fácil utilização. Com uma ampla variedade de símbolos e recursos cartográficos, ele permite a elaboração de sofisticados mapas. O ArcView torna mais fácil as tarefas de gerenciar e editar dados geográficos. Virtualmente qualquer provedor de conteúdo geográfico é capaz de fornecer dados em algum formato compatível com o ArcView, permitindo que uma maior oferta de dados esteja disponível. O ArcView simplifica a maneira de fazer análises ao permitir que as tarefas de processamento sejam definidas em um fluxo lógico de trabalho. Usuários com algum conhecimento em programação poderão customizar o ArcView a partir de linguagens de programação de mercado.

AutoCAD Map - O AutoCAD é uma plataforma SIG para a criação e o gerenciamento de dados espaciais. Este produto apresenta as ferramentas do AutoCAD tradicional num ambiente desenvolvido para profissionais de cartografia. Permite integrar vários tipos de dados e formatos gráficos, possibilitando também fazer análises espaciais. O AutoCAD Map é uma solução que oferece precisão em cartografia e uma poderosa ferramenta de análise SIG para os engenheiros, técnicos de planejamento, gestores de infra-estrutura e geógrafos. Possibilita criar, gerenciar, e produzir mapas, integrar dados de múltiplas fontes e formatos; efetuar análises SIG e produzir mapas temáticos. Possui ferramentas de limpeza de desenhos e simplificadas capacidades de criação de topologias que facilitam a sua utilização. Os usuários podem trabalhar com múltiplos desenhos, e vários usuários podem editar o mesmo mapa simultaneamente. Suporta todos os principais formatos de raster, permitindo a gestão e integração de uma ampla variedade de dados e a utilização de imagens georreferenciadas.

ENVI - O ENVI é um software de processamento de imagens desenvolvido com a linguagem IDL (Interactive Data Language), de quarta geração. Isso lhe garante robustez, velocidade e sofisticação sem necessitar de um equipamento poderoso. A arquitetura aberta do ENVI permite que se obtenham os melhores resultados com imagens fornecidas por sensores de última geração. O livre acesso à linguagem IDL permite que o ENVI possa ser personalizado de acordo com as necessidades do usuário. O ENVI dispõe de funções exclusivas como o visualizador n-dimensional, além de um pacote completo de funções para ortorretificação, elaboração de mosaicos e carta imagem, sofisticadas ferramentas de processamento digital de imagens, visualização e análise de Modelos Digitais do Terreno em três dimensões, dentre outras.

ERDAS - O ERDAS Imagine é a solução, modular, da Leica Geosystems, com um pacote de ferramentas de fácil uso para processamento de imagens, sensoriamento remoto e SIG. Com avançadas funções de modelagem gráfica, ortorretificação, classificação e análise de imagens radar, o usuário tem uma ferramenta de construção e execução de sistemas especialistas em classificação, pós-classificação e modelagem avançada em SIG. 
GRASS - O Geographical Resources Analysis Support System é um Sistema de Informação Geográfica de código aberto de processamento de imagens desenvolvido inicialmente pelo Laboratório de Pesquisas do Corpo de Engenheiros de Construção do Exército Norte-americano (USA/ CERL), desenhado para uso em atividades de planejamento ambiental e gerenciamento de recursos naturais, com interface para outros softwares. É um SIG baseado no formato raster e vetorial, com funções voltadas para processamento de imagens, análise estatística, análise e modelagem espacial, produção de mapas e gráficos e boa interface com banco de dados. Encontram-se também disponíveis funções de digitalização de mapas e conversão de formato vetorial para raster e vice-versa.

IDRISI - Desenvolvido pela Graduate School of Geography da Clark University, Massachussets, baseado no formato raster de representação dos dados e executado em microcomputadores com Sistema Operacional Windows. O IDRISI é um software que reúne ferramentas nas áreas de processamento de imagens, sensoriamento remoto, SIG, geoestatística, apoio a tomada de decisão e análise e modelagem espacial. O usuário pode desenvolver programas específicos de forma a atender novas aplicações. Utiliza banco de dados externo com interface para o Dbase e Access. Permite a migração de dados para outros softwares. Este sistema é indicado para atividades de ensino, pois se trata de um sistema que tem praticamente todas as funções que são normalmente encontradas em um SIG de maior porte, com um custo relativamente baixo.

MAPINFO - O MapInfo é um desktop mapping, com potencialidades semelhantes às do ArcView, que possibilita a visualização de dados geográficos, a análise desses dados e a impressão de mapas. A linguagem de desenvolvimento associada a este produto é o MapBasic, que permite personalizar o MapInfo e integrá-lo com outras aplicações ou aumentar as suas potencialidades básicas. O MapInfo permite realizar análises elaboradas com as extensões SQL como por exemplo, encontrar um endereço, um código postal, um cliente especifico ou outro elemento qualquer; calcular distâncias, áreas ou perímetros; criar ou modificar mapas; etc. Permite trabalhar com uma grande variedade de dados.

SPRING - O Sistema de Processamento de Informações Geo-referenciadas, foi desenvolvido pela Divisão de Processamento de Imagens do Instituto Nacional de Pesquisas Espaciais (INPE), possui versões em português e espanhol. Construído segundo o estado da arte em técnicas de modelagem e programação, combina uma interface com o usuário altamente interativa, interface de banco de dados que modela a metodologia de trabalho em estudos ambientais e manipulação unificada de dados espaciais, o que elimina o dilema raster-vetor. Integra processamento de imagens, análise espacial e modelagem digital do terreno, além de interface com os bancos de dados. Opera em ambiente UNIX e Windows. É baseado num modelo de dados orientados a objetos, projetado especialmente para grandes bases de dados espaciais, são implementados algoritmos inovadores para segmentação e classificação de imagens por regiões, restauração de imagens e geração de grades triangulares. Os dados geográficos são mantidos em um banco de dados relacional que suporta dados provenientes de sistemas comerciais como Dbase, Ingress e Oracle. O sistema de armazenamento suporta representações matriciais e vetoriais de dados geográficos que permitem armazenar de forma organizada e compacta, diversos tipos de mapas temáticos, imagens aéreas, imagens de satélites e imagens de radar

\section{CONSIDERAÇÕES FINAIS}

A sociedade atual esta cada vez mais voltada para o uso das tecnologias e dos computadores, especialmente os jovens, em função de gostarem de trabalhar com computadores e também pela facilidade que normalmente têm em usá-los, facilidade esta favorecida pela falta de medo. Os jovens tendem a experimentar para ver o que acontece, mais do que aprender a teoria e tentar aplicá-la posteriormente. Assim sendo, considera-se que é importante que os Geógrafos comecem a ter a 
consciência que podem não apenas identificar problemas, mas também criar maneiras de tentar resolvê-los, ou apresentar soluções possíveis. Portanto, devemos ser capazes de:

- Saber que dados são necessários e qual o nível de detalhamento;

- Criar uma base de dados e gerenciar dados de diferentes formatos;

- Manipular, analisar, simular e modelar esses dados;

- Saber qual a maneira de apresentar os dados;

- Interpretar os resultados.

Os dados estatísticos são difíceis de interpretar por si só. Transformá-los em mapas e gráficos tornam os mesmos mais fáceis de observar e de encontrar eventuais padrões. Os mapas são especialmente úteis porque, além do componente visual, que facilita a observação, permitem-nos sobrepor diferentes tipos de dados (desde fotografias aéreas, imagens de satélite, e dados estatísticos). Muitas vezes a observação de um mapa é suficiente para se encontrar um padrão de distribuição ou uma relação entre variáveis e sua distribuição espacial. Combinar diferentes grupos de dados e observá-los sob perspectivas diferentes podem ser um método valioso, e a informática permite fazê-lo com rapidez. O computador permite alterar legendas, retirar ou adicionar dados com uma grande rapidez. Depois de explorar os dados existentes e de criar novos dados, é preciso atentar para a transformação da informação em conhecimento geográfico.

No Brasil, à falta de mapeamentos básicos e temáticos em escalas compatíveis com as necessidades, requerem investimento contínuo em técnicas de extração de informação a partir de imagens de satélite, na elaboração de bases cartográficas e na integração de dados. A qualidade dos dados é um fator importante a ser considerado, especialmente no que se refere a completude, atualidade, linhagem, escala, precisão posicional, precisão de atributo e consistência lógica.

O país ainda apresenta carências de dados geográficos, por outro lado os avanços no desenvolvimento e disseminação das tecnologias de informação geográfica, sobretudo as imagens de satélite e software livre, vêm possibilitando, ainda que de forma bastante heterogênea, a geração de informações que têm contribuído para solucionar diversos problemas. O descompasso existente entre a tecnologia disponível e o que os planejadores efetivamente usam para tomar suas decisões, pode ser justificada pelo ritmo lento com que o conhecimento científico e tecnológico se dissemina entre os técnicos e tomadores de decisão, principalmente pelas deficiências na educação superior e na pós-graduação.

\section{REFERÊNCIAS BIBLIOGRAFICAS}

BERTIN, J. Sémiologie graphique. Paris: Mouton et Gauthier-Villars, 1967.

BURROUGH, P. A.; MCDONNELL, R.A. Principles of geographical information systems. Oxford: Oxford University Press, 1998.

BUZAI, G.D. La exploración geodigital. Buenos Aires: Ed. Lugar Editorial, 2000.

CÂMARA, G; CASANOVA, M.A.; HEMERLY, A.; MAGALHÃES, G.C.; MEDEIROS, C.M.B. Anatomia de sistemas de informação geográfica. Campinas: UNICAMP, 10a. Escola de Computação, 1996.

DEMERS, M. N. Fundamentals of geographic information systems. New Jersey, J. Wiley, 2009.

MAGUIRE, D.; GOODCHILD, M.F.; RHIND, D.W. Geographical information systems. Longman Scientific \& Technical, Vol. 1 e 2 ., 1993.

MAGUIRE, D.; GOODCHILD, M.F.; RHIND, D.W. Geographic information systems: principles, and applications. Harlow. Longman Scientific and Technical, 1997. 
MITCHEL, A. The ESRI guide to GIS analysis. Redlands: ESRI, 1999.

TOMLIN, D. Geographic information systems and cartographic modeling. New Jersey, Prentice Hall, Englewood Cliffs, 1990.

TOMLINSON, R. F. Thinking about GIS: Geographic information system planning for managers. ESRI Press, 2005.

XAVIER da SILVA, J.; ZAIDAN, R.T. Geoprocessamento \& análise ambiental: aplicações. Rio de Janeiro: Bertrand Brasil, 2004.

Trabalho enviado em agosto de 2011

Trabalho aceito em outubro de 2011 